\section{BRAZIULAN JOURNAL \\ OF MEDICAL AND BIOLOGICAL RESEARCH}

www.bjournal.com.br
ISSN 1414-431X

Volume 45 (12) 1102-1340 December 2012

\section{BIOMIDICAL SCIENCES}

AND

CLINICAL INVESTIGATION

Braz J Med Biol Res, December 2012, Volume 45(12) 1119-1126

doi: 10.1590/S0100-879X2012007500134

Genetic association of SNPs in the FTO gene and predisposition to obesity in Malaysian Malays

Y.D. Apalasamy, M.F. Ming, S. Rampal, A. Bulgiba and Z. Mohamed

The Brazilian Journal of Medical and Biological Research is partially financed by

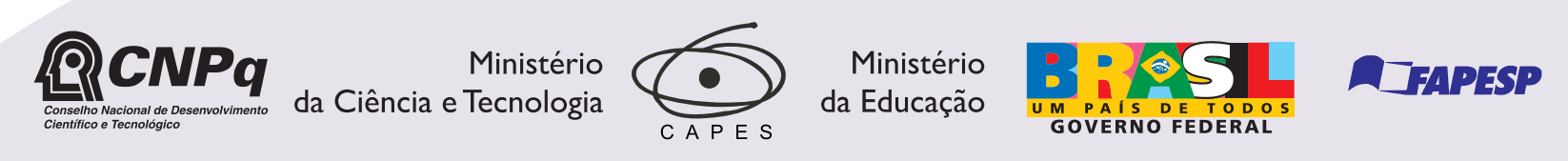

scie/
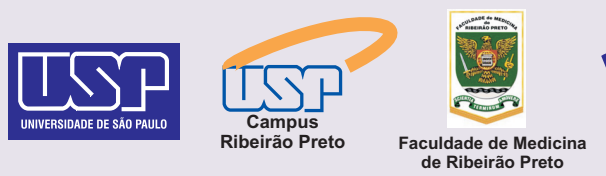

Institutional Sponsors

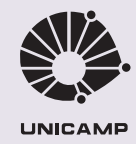

SHIMADZU

$\oplus$ UNICAMP

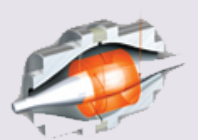

12D Associaçăo Explore High - Performance MS Orbitrap Technology In Proteomics \& Metabolomics

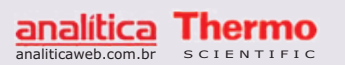




\title{
Genetic association of SNPs in the FTO gene and predisposition to obesity in Malaysian Malays
}

\author{
Y.D. Apalasamy ${ }^{1}$, M.F. Ming ${ }^{2}$, S. Rampal ${ }^{2}$, A. Bulgiba ${ }^{2}$ and Z. Mohamed ${ }^{1}$ \\ ${ }^{1}$ Pharmacogenomics Laboratory, Department of Pharmacology, Faculty of Medicine, \\ University of Malaya, Kuala Lumpur, Malaysia \\ 2Julius Centre University of Malaya, Department of Social and Preventive Medicine, \\ Faculty of Medicine, University of Malaya, Kuala Lumpur, Malaysia
}

\begin{abstract}
The common variants in the fat mass-and obesity-associated (FTO) gene have been previously found to be associated with obesity in various adult populations. The objective of the present study was to investigate whether the single nucleotide polymorphisms (SNPs) and linkage disequilibrium (LD) blocks in various regions of the FTO gene are associated with predisposition to obesity in Malaysian Malays. Thirty-one FTO SNPs were genotyped in 587 (158 obese and 429 non-obese) Malaysian Malay subjects. Obesity traits and lipid profiles were measured and single-marker association testing, LD testing, and haplotype association analysis were performed. LD analysis of the FTO SNPs revealed the presence of 57 regions with complete LD (D' = 1.0). In addition, we detected the association of rs17817288 with low-density lipoprotein cholesterol. The FTO gene may therefore be involved in lipid metabolism in Malaysian Malays. Two haplotype blocks were present in this region of the FTO gene, but no particular haplotype was found to be significantly associated with an increased risk of obesity in Malaysian Malays.
\end{abstract}

Key words: FTO gene; SNP; Obesity; Linkage disequilibrium; Haplotypes

\section{Introduction}

The World Health Organization (WHO) defines overweight as a body mass index (BMI) of $>25 \mathrm{~kg} / \mathrm{m}^{2}$ and obesity as a BMl of $>30 \mathrm{~kg} / \mathrm{m}^{2}$. The $\mathrm{WHO}$ has reported that, globally, overweight and obesity represent the fifth leading risk for death; furthermore, $44 \%$ of the diabetes burden, $23 \%$ of the ischemic heart disease burden, and between 7 and $41 \%$ of certain cancer burdens are related to overweight and obesity. Obesity is a complex disorder, with genetic and non-genetic factors playing crucial roles in an individual's predisposition to it. Many recent studies, including genome-wide association studies (GWAS), have reported that single nucleotide polymorphisms (SNPs) are associated with obesity-related traits in various populations (1-5)

FTO gene variants have been widely studied for their association with obesity. Frayling et al. (1) first discovered in a GWAS that the rs9939609 variant of FTO, with clusters of SNPs in the first intron, was strongly associated with BMI in the UK population. Following this finding, an association between FTO SNPs and obesity traits was detected in people of European ancestry (2), Sardinians (6), and African Americans (7), as well as in a Belgian cohort (8), East Asian population (9), Japanese population $(10,11)$, a Sorbian population in Ger- many (12), a Chinese population in Beijing (13), in an Indian population (14), and many other populations. Compared with other FTO variants, rs9939609 showed the strongest effect on $\mathrm{BMI}$ in these studies.

FTO is expressed in the hypothalamus, a region that is crucial for the control of appetitive behavior $(15,16)$. Animal studies have shown that FTO has an effect on energy homeostasis (17), but the true physiological role of FTO is yet to be explored (18). Although initial reports on FTO stated that the functions and pathways linked to the FTO gene are largely unknown (1), structural analysis of FTO has revealed that it belongs to members of the non-heme 2-oxoglutarate-dependent oxygenase superfamily, which are involved in post-translational modification, DNA repair, and fatty acid metabolism $(19,20)$. Recent studies have suggested that FTO may play an important role in adipogenesis, lipogenesis, and mitochondrial function in skeletal muscle $(21,22)$.

In the current study, our objective was to examine the effects of FTO SNPs on obesity-related traits and to study the linkage disequilibrium (LD) pattern and haplotype block in the Malaysian Malays. To accomplish this, we genotyped 31 SNPs on the FTO gene selected from previous studies and GWAS.

Correspondence: Y.D. Apalasamy, Department of Pharmacology, Faculty of Medicine, University of Malaya, 50603 Kuala Lumpur, Malaysia. E-mail: yamuna219@yahoo.com

Received May 22, 2012. Accepted August 9, 2012. Available online August 24, 2012. Published December 17, 2012. 


\section{Subjects and Methods}

\section{Subjects}

The participants were 587 subjects from the Wellness Program of a public university in Kuala Lumpur, an annual voluntary health screening program for the staff, as well as from a community of the Bera district of Pahang, a State on the east coast of Peninsular Malaysia. All subjects reported that they belonged to the Malay ethnic group for at least three generations. In accordance with the WHO cutoffs for obesity, subjects with a BMl of $30 \mathrm{~kg} / \mathrm{m}^{2}$ were categorized as obese and those with a BMI below $30 \mathrm{~kg} / \mathrm{m}^{2}$ as non-obese. The Medical Ethics Committee (MEC Ref. No. 672.23) of the university Medical Center approved the study protocol and written informed consent was obtained from all participants.

\section{Clinical measurements}

Anthropometric measurements such as height, body weight, BMI, waist circumference, hip circumference, waist-to-hip ratio, systolic blood pressure, and diastolic blood pressure were recorded. After an overnight fast, 10 to $15 \mathrm{~mL}$ blood was collected from each subject for routine biochemical measurements. Total cholesterol, total triglyceride, high-density lipoprotein cholesterol, serum low-density lipoprotein cholesterol (LDL-C), and triglyceride levels were measured using standard clinical laboratory techniques.

\section{DNA isolation from human buccal swabs}

Buccal swabs were collected and genomic DNA was obtained by using the i-genomic CTB DNA extraction kit (iNtRON Biotechnology, Korea). This extraction procedure consists of six main steps: prelysis, lysis, precipitation, DNA binding, washing, and elution with buffers, proteinase $\mathrm{K}$, and RNase $\mathrm{A}$.

\section{DNA measurement}

The concentration and purity of DNA was measured using a Nanodrop spectrophotometer to determine absorbance at wavelengths of 260 and $280 \mathrm{~nm}$ and by agarose gel electrophoresis.

\section{Sequenom MassARRAY ${ }^{\circledR}$ iPLEX Platform (MALDI-TOF)}

Genotyping of 31 SNPs of the FTO gene was performed with the Sequenom MassARRAY platform (Se- quenom, USA). The variants were selected from information provided by previous GWAS and association studies in various populations.

\section{Statistical analysis}

Hardy-Weinberg equilibrium (HWE) was determined in both cases and controls (23) and genotype and allelic frequencies were also determined in cases and controls. Prior to statistical analysis, BMI and triglyceride data were normalized by natural log transformation. The general linear method was used to adjust for age and gender when assessing the effects of SNPs on obesity parameters and lipid levels. The results of association analysis for the SNPs and obesity parameters indicated that the additive model best fitted the data. Data are reported as means \pm SD. Bonferroni's adjustment was performed to correct for multiple tests on multiple markers $(\alpha=0.05 / 30)$. Statistical analysis was performed using the SPSS version 16 software.

LD block construction and haplotype analysis were performed with the Haploview software (version 4.2) to measure the LD coefficient (D'). A permutation test with 5000 replications was used to obtain empirical levels of significance. Adjustment for multiple testing was performed by obtaining $P$ values from the permutation test with the Haploview software. The power of the study, calculated using the Quanto version 1.2.4 software, was $87 \%$.

\section{Results}

Table 1 shows the characteristics of the 587 subjects who participated in the study. The allele frequencies of 30 SNPs in the FTO gene are summarized in Table 2. The FTO
Table 1. Characteristics of the subjects in this study.

\begin{tabular}{lccc}
\hline Characteristics & Non-obese subjects & Obese subjects & Pooled subjects \\
\hline Height $(\mathrm{m})$ & $1.59 \pm 0.09(\mathrm{~N}=429)$ & $1.57 \pm 0.09(\mathrm{~N}=158)$ & $1.58 \pm 0.09(\mathrm{~N}=587)$ \\
Weight $(\mathrm{kg})$ & $63.25 \pm 10.77(\mathrm{~N}=429)$ & $83.32 \pm 11.82(\mathrm{~N}=158)$ & $68.65 \pm 14.20(\mathrm{~N}=587)$ \\
BMI $\left(\mathrm{kg} / \mathrm{m}^{2}\right)$ & $24.92 \pm 3.09(\mathrm{~N}=429)$ & $33.83 \pm 3.18(\mathrm{~N}=158)$ & $27.32 \pm 5.04(\mathrm{~N}=587)$ \\
WC $(\mathrm{cm})$ & $85.25 \pm 10.22(\mathrm{~N}=429)$ & $100.76 \pm 8.57(\mathrm{~N}=158)$ & $89.43 \pm 11.97(\mathrm{~N}=587)$ \\
HC $(\mathrm{cm})$ & $98.17 \pm 7.31(\mathrm{~N}=429)$ & $113.18 \pm 8.04(\mathrm{~N}=158)$ & $102.21 \pm 10.04(\mathrm{~N}=587)$ \\
WHR & $0.87 \pm 0.08(\mathrm{~N}=429)$ & $0.89 \pm 0.07(\mathrm{~N}=158)$ & $0.87 \pm 0.08(\mathrm{~N}=587)$ \\
SBP $(\mathrm{mmHg})$ & $128.55 \pm 17.38(\mathrm{~N}=429)$ & $137.04 \pm 18.32(\mathrm{~N}=158)$ & $130.84 \pm 18.02(\mathrm{~N}=587)$ \\
DBP $(\mathrm{mmHg})$ & $80.46 \pm 11.38(\mathrm{~N}=428)$ & $87.35 \pm 12.28(\mathrm{~N}=158)$ & $82.32 \pm 12.02(\mathrm{~N}=586)$ \\
TG $(\mathrm{mM})$ & $1.42 \pm 0.93(\mathrm{~N}=302)$ & $1.56 \pm 0.67(\mathrm{~N}=107)$ & $1.46 \pm 0.86(\mathrm{~N}=409)$ \\
HDL-C $(\mathrm{mM})$ & $1.32 \pm 0.28(\mathrm{~N}=302)$ & $1.25 \pm 0.25(\mathrm{~N}=107)$ & $1.30 \pm 0.27(\mathrm{~N}=409)$ \\
TC $(\mathrm{mM})$ & $5.49 \pm 0.91(\mathrm{~N}=302)$ & $5.43 \pm 0.98(\mathrm{~N}=107)$ & $5.47 \pm 0.93(\mathrm{~N}=409)$ \\
LDL-C $(\mathrm{mM})$ & $3.53 \pm 0.80(\mathrm{~N}=299)$ & $3.46 \pm 0.87(\mathrm{~N}=106)$ & $3.51 \pm 0.82(\mathrm{~N}=405)$ \\
Age $($ years $)$ & $48.16 \pm 10.19(\mathrm{~N}=429)$ & $48.66 \pm 9.03(\mathrm{~N}=158)$ & $48.29 \pm 9.89(\mathrm{~N}=587)$ \\
\hline
\end{tabular}

Data are reported as means $\pm \mathrm{SD}$, with number of patients within parentheses. $\mathrm{BMI}=$ body mass index; $\mathrm{WC}=$ waist circumference; $\mathrm{HC}=$ hip circumference; $\mathrm{WHR}=$ waist-to-hip ratio; $\mathrm{SBP}=$ systolic blood pressure; $\mathrm{DBP}=$ diastolic blood pressure; $\mathrm{TG}$ = triglyceride; $\mathrm{HDL}-\mathrm{C}=$ high-density lipoprotein cholesterol; TC = total cholesterol; LDL-C = low-density lipoprotein cholesterol. 
Table 2. Allelic distribution among obese and non-obese subjects.

\begin{tabular}{|c|c|c|c|c|c|c|c|c|}
\hline Name & $\begin{array}{l}\text { Chromosome } \\
\text { position }\end{array}$ & MAF & $\begin{array}{l}\text { Assoc. } \\
\text { allele }\end{array}$ & Alleles & $\begin{array}{c}\text { Frequencies } \\
\text { (cases, controls) }\end{array}$ & $x^{2}($ d.f. $=1)$ & $\mathrm{P}$ & $\begin{array}{c}\text { HWE } \\
\text { (cases/controls) }\end{array}$ \\
\hline rs1077128 & 53791653 & 0.336 & G & $\mathrm{G}: \mathrm{T}$ & $0.668,0.662$ & 0.034 & 1.000 & $0.137 / 0.516$ \\
\hline rs11643744 & 53791798 & 0.355 & $\mathrm{G}$ & $A: G$ & $0.370,0.350$ & 0.428 & 1.000 & $0.785 / 0.759$ \\
\hline rs7186521 & 53792922 & 0.32 & $A$ & $A: G$ & $0.684,0.678$ & 0.029 & 1.000 & $0.134 / 0.892$ \\
\hline rs13334933 & 53795636 & 0.337 & $A$ & $A: G$ & $0.671,0.660$ & 0.13 & 1.000 & $0.212 / 0.563$ \\
\hline rs16952517 & 53797057 & 0.27 & $A$ & $\mathrm{G}: \mathrm{A}$ & $0.304,0.258$ & 2.503 & 0.9198 & $0.538 / 0.522$ \\
\hline rs6499643 & 53797518 & 0.226 & $\mathrm{~T}$ & $\mathrm{~T}: \mathrm{C}$ & $0.804,0.763$ & 2.156 & 0.9694 & $0.970 / 0.420$ \\
\hline rs4784323 & 53797565 & 0.129 & G & $\mathrm{G}: \mathrm{A}$ & $0.873,0.869$ & 0.032 & 1.000 & $0.297 / 0.472$ \\
\hline rs7206790 & 53797908 & 0.296 & G & $C: G$ & $0.297,0.295$ & 0.007 & 1.000 & $0.394 / 0.944$ \\
\hline rs9939973 & 53800568 & 0.34 & $A$ & G:A & $0.345,0.338$ & 0.05 & 1.000 & $0.278 / 0.519$ \\
\hline rs1421085 & 53800954 & 0.307 & $\mathrm{C}$ & $\mathrm{T}: \mathrm{C}$ & $0.313,0.304$ & 0.09 & 1.000 & $0.210 / 0.451$ \\
\hline rs1558902 & 53803574 & 0.307 & $A$ & $\mathrm{~T}: \mathrm{A}$ & $0.313,0.304$ & 0.09 & 1.000 & $0.210 / 0.451$ \\
\hline rs10852521 & 53804965 & 0.266 & $\mathrm{C}$ & C:T & $0.741,0.732$ & 0.087 & 1.000 & $0.343 / 0.839$ \\
\hline rs16952522 & 53807498 & 0.156 & G & $C: G$ & $0.171,0.150$ & 0.74 & 1.000 & $0.718 / 0.212$ \\
\hline rs17817288 & 53807764 & 0.298 & G & G:A & $0.709,0.699$ & 0.101 & 1.000 & $0.558 / 0.856$ \\
\hline rs1121980 & 53809247 & 0.342 & $\mathrm{~T}$ & $C: T$ & $0.345,0.340$ & 0.022 & 1.000 & $0.778 / 0.619$ \\
\hline rs16945088 & 53812524 & 0.084 & $A$ & $A: G$ & $0.918,0.915$ & 0.024 & 1.000 & $0.996 / 0.493$ \\
\hline rs17817449 & 53813367 & 0.307 & $\mathrm{G}$ & $\mathrm{T}: \mathrm{G}$ & $0.316,0.303$ & 0.196 & 1.000 & $0.134 / 0.890$ \\
\hline rs8050136 & 53816275 & 0.307 & A & C:A & $0.313,0.304$ & 0.09 & 1.000 & $0.210 / 0.766$ \\
\hline rs9935401 & 53816838 & 0.308 & $A$ & G:A & $0.316,0.305$ & 0.133 & 1.000 & $0.134 / 0.820$ \\
\hline rs3751812 & 53818460 & 0.307 & $\mathrm{~T}$ & $\mathrm{G}: \mathrm{T}$ & $0.313,0.304$ & 0.09 & 1.000 & $0.210 / 0.766$ \\
\hline rs9939609 & 53820527 & 0.307 & A & $\mathrm{T}: \mathrm{A}$ & $0.316,0.304$ & 0.163 & 1.000 & $0.134 / 0.766$ \\
\hline rs7190492 & 53828752 & 0.129 & $A$ & $\mathrm{G}: \mathrm{A}$ & $0.136,0.126$ & 0.214 & 1.000 & $0.165 / 0.598$ \\
\hline rs7204609 & 53833605 & 0.338 & $\mathrm{C}$ & $\mathrm{T}: \mathrm{C}$ & $0.348,0.334$ & 0.191 & 1.000 & $0.703 / 0.278$ \\
\hline rs17218700 & 53844579 & 0.135 & G & $\mathrm{G}: \mathrm{A}$ & $0.886,0.857$ & 1.709 & 0.986 & $0.462 / 0.748$ \\
\hline rs11642841 & 53845487 & 0.145 & C & $C: A$ & $0.864,0.852$ & 0.266 & 1.000 & $0.476 / 0.358$ \\
\hline rs1861867 & 53848561 & 0.126 & $\mathrm{~T}$ & C:T & $0.130,0.125$ & 0.053 & 1.000 & $0.352 / 0.303$ \\
\hline rs11075994 & 53850079 & 0.127 & G & G:A & $0.899,0.864$ & 2.567 & 0.913 & $0.747 / 0.993$ \\
\hline rs1421090 & 53850170 & 0.344 & $\mathrm{C}$ & $\mathrm{T}: \mathrm{C}$ & $0.399,0.324$ & 5.713 & 0.331 & $0.217 / 0.514$ \\
\hline rs17818902 & 53871806 & 0.245 & $\mathrm{~T}$ & $\mathrm{~T}: \mathrm{G}$ & $0.756,0.754$ & 0.006 & 1.000 & $0.810 / 0.613$ \\
\hline rs7191513 & 53990523 & 0.323 & $A$ & $\mathrm{G}: \mathrm{A}$ & $0.348,0.314$ & 1.263 & 0.997 & $0.074 / 0.793$ \\
\hline
\end{tabular}

$\mathrm{MAF}=$ minor allele frequency; d.f. = degrees of freedom; HWE = Hardy-Weinberg equilibrium. ${ }^{*} \mathrm{P}$ value was generated using 5000 permutated chi-squares.

rs1861869 SNP deviated from Hardy-Weinberg equilibrium (HWE case/control $=0.863 / 0.025)$ and was therefore not included in the analysis. After Bonferroni's correction and a permutation test with 5000 replications for the 30 SNPs, there was no significant difference in allelic frequency for any of the FTO SNPs between the obese and non-obese groups. Table 3 shows the genotype frequencies of all FTO SNPs. There was no significant difference in genotype frequency for any of the FTO SNPs between the obese and non-obese groups.

The results of testing the single-marker association of 30 FTO SNPs with obesity traits are summarized in Figure 1. After Bonferroni's adjustment was performed for multiple corrections, $\alpha$ was $0.016(-\log 10 P=2.70)$. The SNP rs 17817288 was significantly associated with LDL-C
$(P=0.001)$ in Malaysian Malays after adjustment for age and gender. None of other SNPs presented a significant association with obesity parameters.

Figure 2 shows the LD pattern of the FTO gene. D prime value (D') of $100 \%$ indicates the complete LD. D' values of $100 \%$ are not shown (the box is empty). The boxes in bright red are with D' values of $100 \%$. The boxes with values of D' $<100 \%$ are in shades of pink or red. When we examined the LD of the FTO region, we found two haplotype blocks of 1 and $44 \mathrm{~kb}$. The strongest LD was seen in the second block, which showed 48 regions with complete LD and 69 regions with high LD ( $\left.D^{\prime}=80-99 \%\right)$.

There are 11 haplotypes in the region of the FTO gene. Table 4 shows the first and second blocks of the FTO haplotypes. The GA, AA, and AG haplotypes in block 1 showed 
frequencies of 36,33 , and $32 \%$, respectively. In block 2 , the TTCCGCATCGGTGCGC, CACCGTAGAATAGTGA, CACGGTAGAATAGTGC, TTTCACATCGGTGTAC, TTTCACATCGGTATGC, and TTCCGCGTCGGTGTGC haplotypes had frequencies of $32,14,14,13,12$, and $5 \%$, respectively. The TTCCATGTCGGTGTGC and CACC GTAGAATAGTGC haplotypes had lower frequencies $(<5 \%)$. There were no significant differences in haplotype frequencies between obese and non-obese subjects. After permutation test correction with 5000 permutations, none of the haplotypes was associated with obesity.

\section{Discussion}

There were no significant differences in allelic or genotype frequencies of the 30 FTO SNPs between the obese and non-obese groups in the Malaysian Malay population. Recent studies have pointed out that the SNPs in the FTO gene contribute to obesity and obesity-related traits in various populations around the globe (1,3,24-27). Singlemarker analysis revealed that $\mathrm{rs} 17817288$ was significantly associated with LDL-C levels $(P=0.001)$ in Malaysian Malays. A recent study (22) showed that, as a transcriptional coactivator, FTO might play an important role in the transcriptional regulation of adipogenesis and suggested that FTO might be involved in the regulation of fat development and maintenance. Therefore, we speculated that the FTO rs17817288 SNP may have an effect on adipogenesis in Malaysian Malays, which is consistent with findings by Wu et al. (22) concerning the functional effects of the FTO gene. The FTO rs9939609 SNP was chosen as representative of FTO SNPs in the present study because this locus was highlighted in many studies as having the strongest effect on obesity; it was also the key signal identified in the GWAS (1). A meta-analysis reported that 21 of 29 studies have shown a significant association between obesity and rs9939609 (5). However, this SNP had no effect on obesity in the Malaysian Malay population.

A meta-analysis reported that the minor allele frequency (MAF) for rs9939609 varies across the global population. The MAF of the FTO rs9939609 polymorphism was lower (0.31) in the Malaysian Malay population compared to the previously reported range of 0.38 to 0.46 in European populations $(1,8,28)$. For example, the MAF was 0.31 to 0.37 in Hispanics, 0.34 to 0.44 in Caucasians, 0.17 in South Americans, 0.36 in Africans, 0.11 to 0.20 in Asians, 0.25 in Singaporean Malays, 0.13 in Singaporean Chinese, and 0.42 in Singaporean Indians $(5,29,30)$. In addition, the MAF for rs1421085, rs1558902, rs17817449, rs3751812, rs9939609, and rs8050136 was similar across these six SNPs. The MAF for the SNPs is 0.31 .

We investigated the LD structure of the FTO SNPs in Malaysian Malays. Linkage analysis showed 57 regions with complete LD in the FTO gene. Our results showed that 15 of the 30 FTO SNPs $(50 \%)$ are in high LD ( $D \geq 0.88)$ with
Table 3. Genotype distribution among obese and non-obese subjects.

\begin{tabular}{|c|c|c|c|c|c|c|}
\hline \multirow[b]{2}{*}{ rs1077128 } & \multicolumn{3}{|c|}{ Non-obese } & \multicolumn{3}{|c|}{ Obese } \\
\hline & GG & GT & TT & GG & GT & TT \\
\hline & 43.12 & 46.15 & 10.72 & 47.47 & 38.61 & 13.92 \\
\hline \multirow[t]{2}{*}{ rs 10852521} & $\mathrm{CC}$ & TC & TT & $\mathrm{CC}$ & TC & TT \\
\hline & 53.38 & 39.63 & 6.99 & 56.33 & 35.44 & 8.23 \\
\hline \multirow[t]{2}{*}{ rs11075994 } & AA & $A G$ & GG & AA & $A G$ & GG \\
\hline & 1.86 & 23.54 & 74.59 & 1.27 & 17.72 & 81.01 \\
\hline \multirow[t]{2}{*}{ rs1121980 } & CC & TC & TT & $\mathrm{CC}$ & TC & TT \\
\hline & 44.06 & 43.82 & 12.12 & 44.94 & 41.14 & 13.92 \\
\hline \multirow[t]{2}{*}{ rs11642841 } & AA & CA & CC & AA & $\mathrm{CA}$ & CC \\
\hline & 1.63 & 26.34 & 72.03 & 2.53 & 22.15 & 75.32 \\
\hline \multirow[t]{2}{*}{ rs11643744 } & AA & GA & GG & AA & GA & GG \\
\hline & 41.96 & 46.15 & 11.89 & 39.24 & 47.47 & 13.29 \\
\hline \multirow[t]{2}{*}{ rs13334933 } & AA & $A G$ & GG & AA & AG & GG \\
\hline & 42.89 & 46.15 & 10.96 & 47.47 & 39.24 & 13.29 \\
\hline \multirow{2}{*}{ rs1421085 } & CC & CT & TT & $\mathrm{CC}$ & CT & TT \\
\hline & 10.03 & 40.79 & 49.18 & 12.03 & 38.61 & 49.37 \\
\hline \multirow[t]{2}{*}{ rs1421090 } & CC & $\mathrm{CT}$ & $\mathrm{TT}$ & $\mathrm{CC}$ & $\mathrm{CT}$ & $\mathrm{TT}$ \\
\hline & 11.19 & 42.42 & 46.39 & 18.35 & 43.04 & 38.61 \\
\hline \multirow[t]{2}{*}{ rs1558902 } & AA & AT & $\mathrm{TT}$ & AA & AT & TT \\
\hline & 10.02 & 40.79 & 49.18 & 12.03 & 38.61 & 49.37 \\
\hline \multirow{2}{*}{ rs16945088 } & AA & AG & GG & AA & $A G$ & GG \\
\hline & 83.45 & 16.08 & 0.47 & 84.18 & 15.19 & 0.63 \\
\hline \multirow[t]{2}{*}{ rs16952517 } & AA & AG & GG & AA & AG & GG \\
\hline & 7.23 & 37.06 & 55.71 & 10.13 & 40.51 & 49.37 \\
\hline \multirow[t]{2}{*}{ rs 16952522} & $\mathrm{CC}$ & $\mathrm{GC}$ & GG & $\mathrm{CC}$ & $\mathrm{GC}$ & GG \\
\hline & 72.96 & 24.01 & 3.03 & 68.35 & 29.11 & 2.53 \\
\hline rs17218700 & AA & AG & GG & AA & $A G$ & GG \\
\hline & 1.86 & 24.94 & 73.19 & 1.9 & 18.99 & 79.11 \\
\hline rs17817288 & AA & $A G$ & GG & AA & $A G$ & GG \\
\hline & 8.86 & 42.42 & 48.72 & 9.49 & 39.24 & 51.27 \\
\hline rs 1861867 & GG & GT & TT & GG & GT & TT \\
\hline & 77.16 & 20.75 & 2.1 & 76.58 & 20.89 & 2.53 \\
\hline rs3751812 & GG & GT & TT & GG & GT & TT \\
\hline & 48.72 & 41.72 & 9.56 & 49.37 & 38.61 & 12.03 \\
\hline rs 4784323 & AA & GA & GG & AA & GA & GG \\
\hline & 2.1 & 21.91 & 75.99 & 2.53 & 20.25 & 77.22 \\
\hline rs6499643 & CC & TC & TT & CC & TC & TT \\
\hline & 4.9 & 37.53 & 57.58 & 3.8 & 31.65 & 64.56 \\
\hline rs7186521 & AA & GA & GG & AA & GA & GG \\
\hline & 46.15 & 43.36 & 10.49 & 49.37 & 37.97 & 12.66 \\
\hline rs7190492 & AA & AG & GG & AA & $A G$ & GG \\
\hline & 1.86 & 21.45 & 76.69 & 3.16 & 20.89 & 75.95 \\
\hline rs7191513 & $\mathrm{AA}$ & GA & GG & AA & GA & GG \\
\hline & 9.55 & 43.59 & 46.85 & 15.19 & 39.24 & 45.57 \\
\hline rs7204609 & CC & TC & TT & $\mathrm{CC}$ & TC & TT \\
\hline & 12.35 & 42.19 & 45.45 & 12.66 & 44.3 & 43.04 \\
\hline rs7206790 & $\mathrm{CC}$ & CG & GG & $\mathrm{CC}$ & CG & GG \\
\hline & 49.65 & 41.72 & 8.62 & 50.63 & 39.24 & 10.13 \\
\hline rs8050136 & $\mathrm{AA}$ & $\mathrm{CA}$ & CC & AA & CA & CC \\
\hline & 9.56 & 41.72 & 48.72 & 12.03 & 38.61 & 49.37 \\
\hline rs9935401 & AA & GA & GG & AA & GA & GG \\
\hline & 9.56 & 41.96 & 48.48 & 12.66 & 37.97 & 49.37 \\
\hline rs9939609 & AA & AT & TT & AA & AT & TT \\
\hline & 9.56 & 41.72 & 48.72 & 12.66 & 37.97 & 49.37 \\
\hline rs9939973 & $\mathrm{AA}$ & AG & GG & AA & AG & GG \\
\hline & 12.12 & 43.36 & 44.52 & 13.92 & 41.14 & 44.94 \\
\hline rs17817449 & GG & GT & TT & GG & GT & TT \\
\hline & 9.32 & 41.96 & 48.72 & 12.66 & 37.97 & 49.37 \\
\hline rs17818902 & GG & GT & TT & GG & GT & $\mathrm{TT}$ \\
\hline & 5.59 & 38 & 56.41 & 6.33 & 36.08 & 57.59 \\
\hline
\end{tabular}

${ }^{*} P$ value was generated using the chi-square test. There was no significant difference in genotype frequency of each of the SNP between the obese and non-obese subjects. 


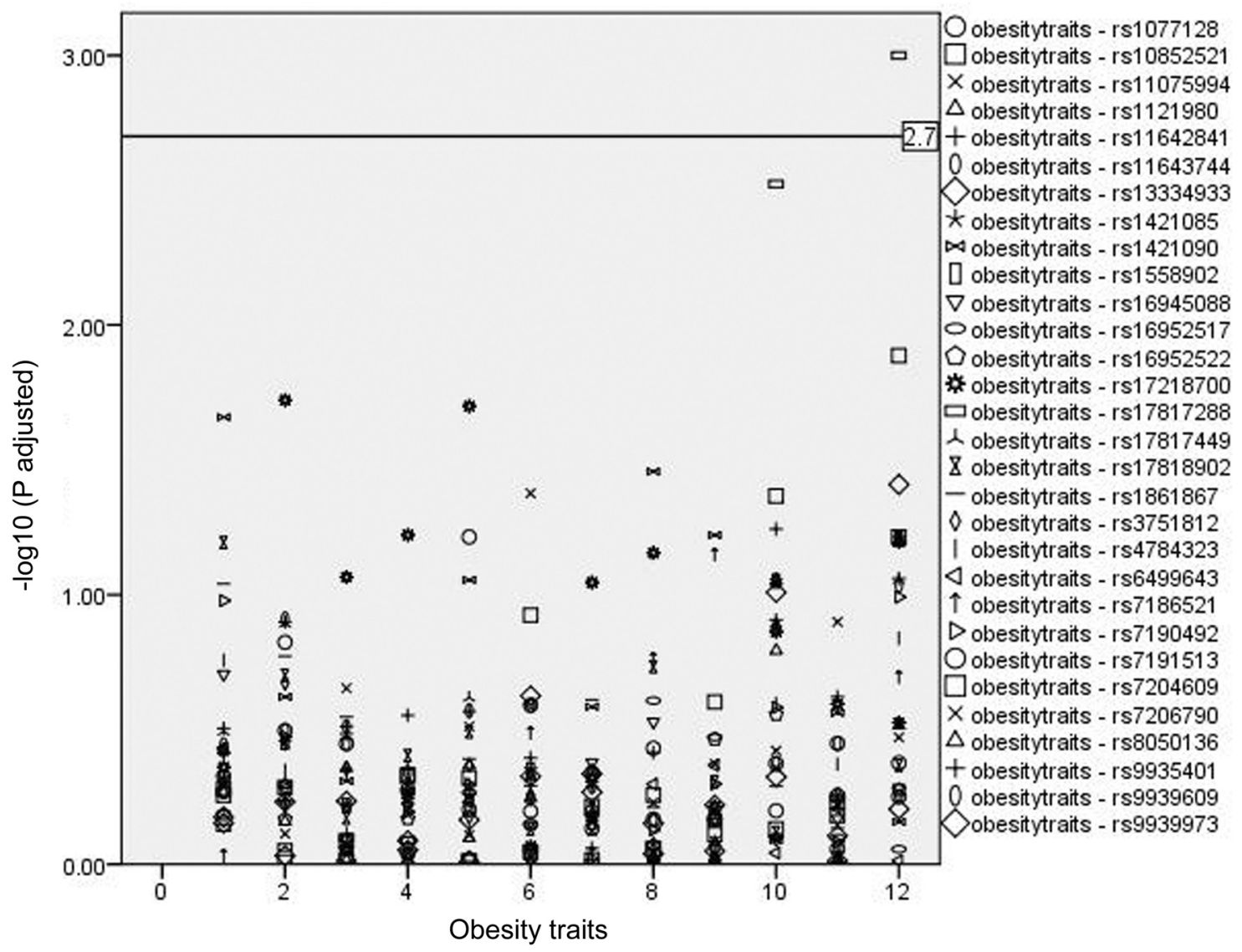

Figure 1. Log10 of the $P$ value for single-marker association of FTO SNPs with obesity traits after adjustment for age and gender. X-axis: $1=$ height; $2=$ weight: $3=\operatorname{logBMI} ; 4=$ WC; $5=\mathrm{HC} ; 6=$ WHR; $7=\mathrm{SBP} ; 8=\mathrm{DBP} ; 9=\log \mathrm{TG} ; 10=\mathrm{TC} ; 11=$ HDL-C; 12 = LDL-C. For abbreviations, see legend to Table 1.

rs9939609. This indicates that the FTO SNPs in the first intron of the FTO gene are high in LD in Malaysian Malays. In our samples, three SNPs, rs9935401, rs16945088, and rs10852521 (D'=1.0), were in complete LD with rs9939609. In the HapMap sample of Utah residents with ancestry from northern and western Europe (CEU), the three SNPs rs10852521, rs16945088, and rs9935401 are in complete LD ( $\left.D^{\prime}=1.0\right)$ with rs9939609, as observed in our sample of Malaysian Malays. In contrast, in the HapMap sample of Yoruba in Ibadan, Nigeria (YRI), the rs9939609 at rs10852521 is not in strong LD $\left(D^{\prime}=0.48\right)$. Complete LD $(D=1.0)$ with rs9939609 at rs16945088 and at rs17817449 has been shown in HapMap samples of African ancestry in Southwest USA (ASW); Utah residents with northern and western European ancestry (CEU); Han Chinese in Beijing, China (CHB); Chinese in Metropolitan Denver, Colorado (CHD); Gujarati Indians in Houston, Texas (GIH); Japanese in Tokyo, Japan (JPT); Luhya in Webuye, Kenya (LWK); Mexican ancestry in Los Angeles, California (MEX); Tuscans in Italy (TSI), and Yoruba in Ibadan, Nigeria (YRI). A similar LD strength was observed in our samples of Malaysian Malays. Interestingly, results from HapMap samples show that rs9939609 is in complete LD with rs10852521 with samples from Asia (JPT, CHD, and CHB), which was also replicated in our samples of Malaysian Malays. In contrast, the strength of LD of rs9939609 at rs 10852521 is reduced in samples of African ancestry such as YRI, ASW, LWK, and Maasai in Kinyawa, Kenya (MKK; D > 0.35) (31).

The Singaporean Genome Variation Project analyzed the LD in 98 Singaporean Malays (MAS) with the Affymetric Genome-Wide Human SNP Array and the Illumina Human $1 \mathrm{M}$ single-sample BeadChip genotyping platforms (29). In our study, we found that the LD pattern of all regions with complete LD in Malaysian Malays was similar to the MAS samples except for rs 17218700 and rs7190492. The LD of rs17218700 with rs7190492 was lower in the MAS samples $\left(D^{\prime}=0.74\right)$ compared with those in our study. By using the Sequenom MassARRAY ${ }^{\circledR}$ iPLEX platform with a 


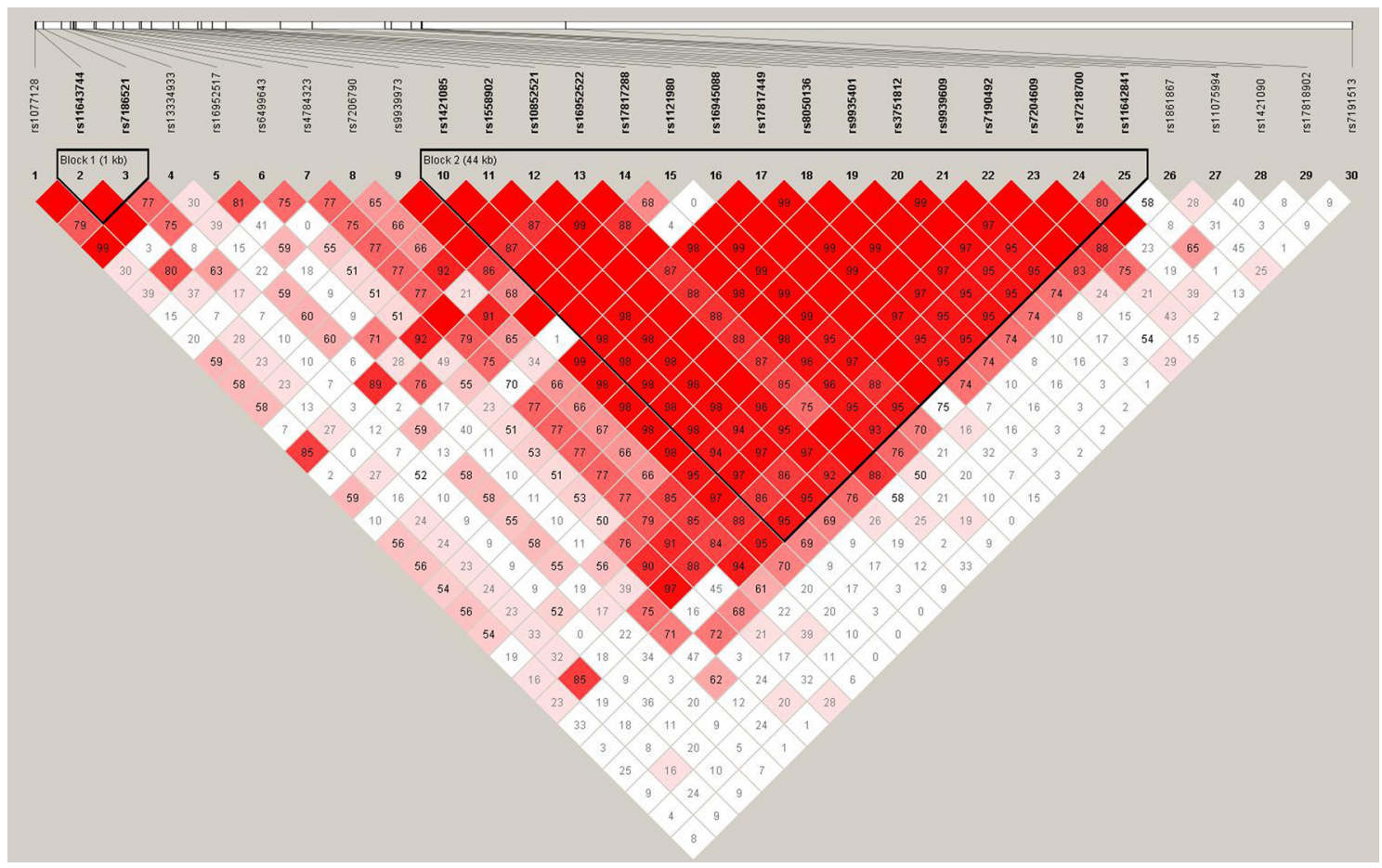

Figure 2. Linkage disequilibrium pattern of FTO single nucleotide polymorphisms. D prime value (D') of $100 \%$ indicates the complete LD. D' values of $100 \%$ are not shown (the box is empty). The boxes in bright red are with D' values of $100 \%$. The boxes with values of $D^{\prime}<100 \%$ are in shades of pink or red.

much larger sample size ( $N=587)$, we found that the LD pattern from our own data for Malaysian Malays is very similar to that of the MAS samples. Therefore, we can predict a

Table 4. Haplotype analysis of the FTO gene.

\begin{tabular}{lll}
\hline Haplotype & Frequency & $\begin{array}{c}\text { Frequencies } \\
\text { (cases, controls) }\end{array}$ \\
\hline Block 1 & & \\
GA & 0.355 & $0.370,0.350$ \\
AA & 0.325 & $0.313,0.329$ \\
AG & 0.32 & $0.316,0.322$ \\
Block 2 & & \\
TTCCGCATCGGTGCGC & 0.324 & $0.330,0.324$ \\
CACCGTAGAATAGTGA & 0.139 & $0.130,0.144$ \\
CACGGTAGAATAGTGC & 0.138 & $0.152,0.134$ \\
TTTCACATCGGTGTAC & 0.131 & $0.114,0.138$ \\
TTTCACATCGGTATGC & 0.123 & $0.133,0.121$ \\
TTCCGCGTCGGTGTGC & 0.053 & $0.054,0.053$ \\
TTCCATGTCGGTGTGC & 0.032 & $0.029,0.033$ \\
CACCGTAGAATAGTGC & 0.022 & $0.026,0.021$ \\
\hline
\end{tabular}

${ }^{*} P$ value was generated using 5000 permutated chi-squares. There was no significant difference in haplotype frequency of each of the haplotypes between the obese and non-obese subjects. similar pattern of LD in the FTO gene ancestry of Malays in Southeast Asia because of the genetic homogeneity. Further studies will be needed to address this pattern in Malays in other parts of Southeast Asia.

Differences exist in the LD structure of the FTO gene in diverse ethnic populations (5). For example, previous studies have shown that the degree of $L D$ in a population with African ancestry is lower than that in European populations (32). Recent studies have reported that the genetic variability in the FTO gene that is in high LD are associated with a risk of obesity in Spanish (33) and African Americans (27). Our study showed novel patterns of LD in the FTO gene ancestry of Malaysian Malays.

Most FTO haplotypes were found to have frequencies of more than $5 \%$ in Malaysian Malays. We identified major haplotypes in people of Malaysian Malay ancestry that may also be present in Malays in other parts of Southeast Asia. Studies of different populations will be needed, however, to confirm this finding. The haplotypes in block 1 and block 2 of the FTO gene were not associated with obesity in Malaysian Malays.

Previous studies on the association of the FTO gene with obesity included between 240 and 5380 subjects from populations across the globe (5). Although the sample investigated in the present study was of moderate size in comparison with other studies, this study was sufficiently 
powered with the population of Malaysian Malays. Since the participants of this study are middle-aged and elderly individuals, these findings cannot be generally extrapolated to children and adolescents in Malaysia. This study was conducted in Malaysian Malays, and we cannot generalize these findings to overall Malaysian populations such as Chinese, Indians and other ethnic groups in Malaysia. Therefore, large-scale genetic association studies on FTO should be carried out in future in other ethnic groups within the Malaysian population.

To the best of our knowledge, this is the first study on genetic variants in the FTO gene in Malaysian Malays. We conclude that the genetic variations in the FTO gene are in high LD in this ethnic group. Two haplotype blocks of FTO were identified, neither of which confers an increased risk for obesity in this population. We detected the association of rs 17817288 with LDL-C, and this SNP may be involved in lipid metabolism in Malaysian Malays. Replication of this association in larger samples and in functional molecular

\section{References}

1. Frayling TM, Timpson NJ, Weedon MN, Zeggini E, Freathy $\mathrm{RM}$, Lindgren CM, et al. A common variant in the FTO gene is associated with body mass index and predisposes to childhood and adult obesity. Science 2007; 316: 889-894.

2. Dina C, Meyre D, Gallina S, Durand E, Korner A, Jacobson $P$, et al. Variation in FTO contributes to childhood obesity and severe adult obesity. Nat Genet 2007; 39: 724-726.

3. Zhang G, Karns R, Narancic NS, Sun G, Cheng H, Missoni $\mathrm{S}$, et al. Common SNPs in FTO gene are associated with obesity related anthropometric traits in an island population from the eastern Adriatic coast of Croatia. PLoS One 2010; 5: e10375.

4. Apalasamy YD, Ming MF, Rampal S, Bulgiba A, Mohamed Z. Gender-dependent association of a beta2-adrenergic gene variant with obesity parameters in Malaysian Malays. Asia Pac J Public Health 2011 [ahead of print].

5. Peng S, Zhu Y, Xu F, Ren X, Li X, Lai M. FTO gene polymorphisms and obesity risk: a meta-analysis. BMC Med 2011; 9: 71.

6. Scuteri A, Sanna S, Chen WM, Uda M, Albai G, Strait J, et al. Genome-wide association scan shows genetic variants in the FTO gene are associated with obesity-related traits. PLoS Genet 2007; 3: e115.

7. Wing MR, Ziegler J, Langefeld CD, Ng MC, Haffner SM, Norris JM, et al. Analysis of FTO gene variants with measures of obesity and glucose homeostasis in the IRAS Family Study. Hum Genet 2009; 125: 615-626.

8. Peeters A, Beckers S, Verrijken A, Roevens P, Peeters P, Van Gaal L, et al. Variants in the FTO gene are associated with common obesity in the Belgian population. Mol Genet Metab 2008; 93: 481-484.

9. Deka R, Xu L, Pal P, Toelupe PT, Laumoli TS, Xi H, et al. A tagging SNP in INSIG2 is associated with obesity-related phenotypes among Samoans. BMC Med Genet 2009; 10: 143.

10. Hotta K, Nakata Y, Matsuo T, Kamohara S, Kotani K, Ko- studies will further increase the validity of this association and the causative relationship between the FTO variant and LDL-C.

\section{Acknowledgments}

We are grateful to the Wellness Program team of the University of Malaya, Malaysia, the medical students who assisted in data collection, and all the participants in this study. Further thanks go to Associate Professor Agus Salim (National University of Singapore), Professor Rosmawati Mohamed (University of Malaya), Dr. Batoul Saadat Haerian (University of Malaya), Ms. Devi Peramalah (University of Malaya), Sim Maw Shin (University of Malaya), and Shamsul Mohd Zain (University of Malaya) for advising and helping with data analysis. Research supported by University of Malaya (\#RG075-09HTM, \#PS383-2009B) and HIR-MOHE (\#E000049-20001).

matsu R, et al. Variations in the FTO gene are associated with severe obesity in the Japanese. J Hum Genet 2008; 53: 546-553.

11. Karasawa S, Daimon M, Sasaki S, Toriyama S, Oizumi T, Susa S, et al. Association of the common fat mass and obesity associated (FTO) gene polymorphism with obesity in a Japanese population. Endocr J 2010; 57: 293-301.

12. Tonjes A, Zeggini E, Kovacs P, Bottcher Y, Schleinitz D, Dietrich K, et al. Association of FTO variants with BMI and fat mass in the self-contained population of Sorbs in Germany. Eur J Hum Genet 2010; 18: 104-110.

13. Xi B, Shen $Y$, Zhang M, Liu X, Zhao X, Wu L, et al. The common rs9939609 variant of the fat mass and obesityassociated gene is associated with obesity risk in children and adolescents of Beijing, China. BMC Med Genet 2010; 11: 107.

14. Chauhan G, Tabassum R, Mahajan A, Dwivedi OP, Mahendran Y, Kaur I, et al. Common variants of FTO and the risk of obesity and type 2 diabetes in Indians. J Hum Genet 2011; 56: 720-726.

15. Stratigopoulos G, Padilla SL, LeDuc CA, Watson E, Hattersley AT, McCarthy MI, et al. Regulation of Fto/Ftm gene expression in mice and humans. Am J Physiol Regul Integr Comp Physiol 2008; 294: R1185-R1196.

16. Gerken T, Girard CA, Tung YC, Webby CJ, Saudek V, Hewitson KS, et al. The obesity-associated FTO gene encodes a 2-oxoglutarate-dependent nucleic acid demethylase. Science 2007; 318: 1469-1472.

17. Fischer J, Koch L, Emmerling C, Vierkotten J, Peters T, Bruning JC, et al. Inactivation of the Fto gene protects from obesity. Nature 2009; 458: 894-898.

18. Larder R, Cheung MK, Tung YC, Yeo GS, Coll AP. Where to go with FTO? Trends Endocrinol Metab 2011; 22: 53-59.

19. Ozer A, Bruick RK. Non-heme dioxygenases: cellular sensors and regulators jelly rolled into one? Nat Chem Biol 2007; 3: 144-153. 
20. Clifton IJ, McDonough MA, Ehrismann D, Kershaw NJ, Granatino N, Schofield CJ. Structural studies on 2-oxoglutarate oxygenases and related double-stranded beta-helix fold proteins. J Inorg Biochem 2006; 100: 644-669.

21. Bravard A, Lefai E, Meugnier E, Pesenti S, Disse E, Vouillarmet $\mathrm{J}$, et al. FTO is increased in muscle during type 2 diabetes, and its overexpression in myotubes alters insulin signaling, enhances lipogenesis and ROS production, and induces mitochondrial dysfunction. Diabetes 2011; 60: 258268.

22. Wu Q, Saunders RA, Szkudlarek-Mikho M, Serna IL, Chin $\mathrm{KV}$. The obesity-associated Fto gene is a transcriptional coactivator. Biochem Biophys Res Commun 2010; 401: 390-395.

23. Rodriguez S, Gaunt TR, Day IN. Hardy-Weinberg equilibrium testing of biological ascertainment for Mendelian randomization studies. Am J Epidemiol 2009; 169: 505-514.

24. Maes HH, Neale MC, Eaves LJ. Genetic and environmental factors in relative body weight and human adiposity. Behav Genet 1997; 27: 325-351.

25. Hunt SC, Stone S, Xin Y, Scherer CA, Magness CL, ladonato SP, et al. Association of the FTO gene with BMI. Obesity 2008; 16: 902-904.

26. Al-Attar SA, Pollex RL, Ban MR, Young TK, Bjerregaard P, Anand SS, et al. Association between the FTO rs9939609 polymorphism and the metabolic syndrome in a non-Caucasian multi-ethnic sample. Cardiovasc Diabetol 2008; 7 : 5.
27. Hassanein MT, Lyon HN, Nguyen TT, Akylbekova EL, Waters K, Lettre G, et al. Fine mapping of the association with obesity at the FTO locus in African-derived populations. Hum Mol Genet 2010; 19: 2907-2916.

28. Hinney A, Nguyen TT, Scherag A, Friedel S, Bronner G, Muller TD, et al. Genome wide association (GWA) study for early onset extreme obesity supports the role of fat mass and obesity associated gene (FTO) variants. PLoS One 2007; 2 : e1361.

29. Teo YY, Sim X, Ong RT, Tan AK, Chen J, Tantoso E, et al. Singapore Genome Variation Project: a haplotype map of three Southeast Asian populations. Genome Res 2009; 19: 2154-2162.

30. Hennig BJ, Fulford AJ, Sirugo G, Rayco-Solon P, Hattersley AT, Frayling TM, et al. FTO gene variation and measures of body mass in an African population. BMC Med Genet 2009; 10: 21.

31. Frazer KA, Ballinger DG, Cox DR, Hinds DA, Stuve LL, Gibbs RA, et al. A second generation human haplotype map of over 3.1 million SNPs. Nature 2007; 449: 851-861.

32. Reich DE, Cargill M, Bolk S, Ireland J, Sabeti PC, Richter DJ, et al. Linkage disequilibrium in the human genome. Nature 2001; 411: 199-204.

33. Gonzalez JR, Gonzalez-Carpio M, Hernandez-Saez R, Serrano Vargas V, Torres HG, Rubio-Rodrigo M, et al. FTO risk haplotype among early onset and severe obesity cases in a population of western Spain. Obesity 2012; 20: 909-915. 